\title{
Testing of Milliwatt Power Source Components
}

\author{
G. J. Snyder ${ }^{1}$, A. Borshchevsky ${ }^{1}$, A. Zoltan ${ }^{1}$, T. Caillat ${ }^{1}$, J.-P. Fleurial ${ }^{1}$, B. Nesmith ${ }^{1}$, J. Mondt ${ }^{1}$, T. McBirney ${ }^{2}$, D. Allen, J. \\ C. Bass, S. Ghamaty, N. Elsner ${ }^{3}$, L. Anatychuk ${ }^{4}$ \\ ${ }^{1}$ Jet Propulsion Laboratory/California Institute of Technology, Pasadena CA 91109 \\ ${ }^{2}$ Swales Aerospace, 5050 Powder Mill Road, Beltsville, MD 20705 \\ ${ }^{3} \mathrm{Hi}-\mathrm{Z}$ Technology, 7606 Miramar Road, San Diego, CA 92126 \\ ${ }^{4}$ Institute of Thermoelectricity, Chernivtsi, Ukraine \\ (818)354-0988;jsnyder@jpl.nasa.gov
}

\begin{abstract}
A milliwatt power source (MPS) has been developed to satisfy the requirements of several potential solar system exploration missions. The MPS is a small power source consisting of three major components: a space qualified heat source (RHU), a thermopile (thermoelectric converter or TEC) and a container to direct the RHU heat to the TEC. Thermopiles from Hi-Z Technology, Inc. of San Diego and the Institute of Thermoelectricity of Chernivtsi Ukraine suitable for the MPS were tested and shown to perform as expected, producing $40 \mathrm{~mW}$ of power with a temperature difference of about $170^{\circ} \mathrm{C}$. Such thermopiles were successfully life tested for up to a year. A MPS container designed and built by Swales Aerospace was tested with both a TEC simulator and actual TEC. The Swales unit, tested under dynamic vacuum, provided less temperature difference than anticipated, such that the TEC produced $20 \mathrm{~mW}$ of power with heat input equivalent to a RHU.
\end{abstract}

\section{Introduction}

Several potential solar system exploration missions are being developed that require a power source smaller than the current redioisotope thermoelectric generator (RTG) or planned advanced radioisotope power source (ARPS). Several systems have been proposed utilizing the standard radio isotope heater unit (RHU) as a heat source. The RHU was developed by DOE for the Galileo and Ulysses missions to maintain specific spacecraft components within normal operating temperatures. The RHU provides $1 \mathrm{~W}$ of heat and can be expected to produce about $40 \mathrm{~mW}$ of electrical power using a thermoelectric generator. Using a MPS instead of only a RHU will provide electrical power in addition to $96 \%$ of the RHU heat. These electrical power systems, generally called milliwatt power sources (MPS) have also been referred to as the "powerstick" concept (Chmielewski, 1994). Various MPS systems have been developed at tested in Russia for terrestrial and space applications (Pustovalov, 1999).

The MPS is designed to be used in a small planetary rover, small communication transmitter, microspacecraft or an autonomous science package such as a remote weather station, that either uses continuous power at a level of a fraction of a watt or can operate intermittently by using energy from a battery that is continuously charged by a MPS. For example, the proposed Mars Network missions (e.g. PASCAL) could take advantage of MPS's for their minimeteorological stations. The MPS is designed to produce enough continuous power to operate a sequencer while trickle charging the batteries. The battery power could then be used every couple of weeks to operate the instruments and transmit the data. Without such a power source, it will be difficult to power such missions for the nearly 20 year duration, particularly in the polar regions.

\section{Milliwatt Power Source Description}

The MPS contains three essential components: the RHU heat source, the thermoelectric converter (TEC), and container. The MPS will probably also require a rechargeable battery. The RHU heat source supplies heat to the thermoelectric converter or thermopile, which produces electricity used to charge the lithium ion battery. The container is essential in that it directs the heat from the RHU into the TEC.

The waste heat from the RHU is used to keep the battery warm, as well as other spacecraft components. The energy stored in the battery can be used periodically to operate a science instrument. A small amount of power is also available continuously from the thermopile.

\section{Radioisotope Heater Unit (RHU)}

The RHU, or specifically the light weight RHU, is a standard heat source produced by DoE and designed to provide $1.1 \mathrm{~W}$ of thermal power (Tate, 1982) at the start of mission. The unit is a cylinder $32 \mathrm{~mm}$ high, $26 \mathrm{~mm}$ in diameter and weighs about $40 \mathrm{~g}$. In the unit, the pelletized $\mathrm{Pu}$ 238 fuel is surrounded by platinum-alloy capsule, pyrolytic graphite thermal insulation and high technology graphite ablation shell. Over a hundred of these units are used in space such as on the Galileo and Cassini spacecrafts. The Pu-238 fuel has a half life of 88 years, providing power for decades as evidenced by the continuing operation of the Voyager spacecrafts. The remaining heat from the RHU in the MPS is used to keep the battery warm. The electrical imitators of RHU were designed and built at JPL and are used in place if actual RHU's for testing.

\section{Thermoelectric Converter (TEC) or Thermopile}

The thermoelectric converter, also called thermoelectric module or thermopile has been developed by $\mathrm{Hi}-\mathrm{Z}$ Technology, Inc. (Elsner, 1999). It uses $\mathrm{Bi}_{2} \mathrm{Te}_{3}$-based materials, both n- and p-type. The materials are vacuum hotpressed to provide the strength and machining characteristics required to fabricate the long thin legs for the module. The module consists of $18 \times 18$ array of legs. Each leg is $0.381 \mathrm{~mm}$ on a side and $22.86 \mathrm{~mm}$ long (Fig. 1). Such a solid array should have superior strength and excellent shock and vibration characteristics. A $0.025 \mathrm{~mm}$ thick layer of insulating film is used within the interior of the module to electrically separate the legs. The module is expected to have a peak power output of at least $40 \mathrm{~mW}$ in a generator using the $1 \mathrm{~W}$ RHU as a heat source. The matched load voltage will 
be 5 volts. The weight of the module is about $7 \mathrm{~g}$. The Institute of Thermoelectricity in Chernivtsi, Ukraine is also capable of making such thermopiles using a similar fabrication process. Their designation of this thermopile design is Altec 1050.

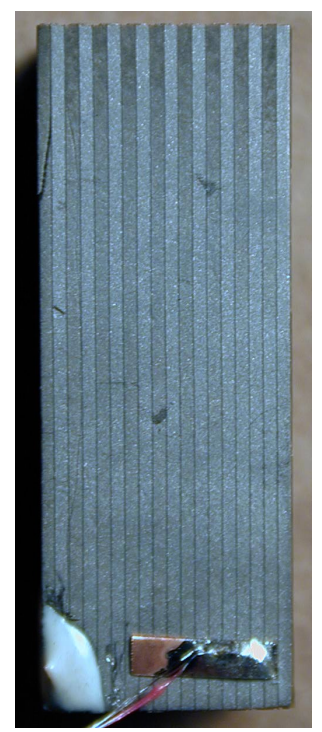

(a)

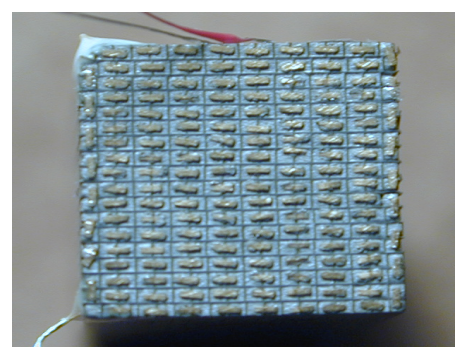

(b)
Figure 1. Thermoelectric Module Developed by Hi-Z, (a). Side View Showing Apparent Crack and Attached Thermocouple. (b). Cold End Showing Interconnects.

One Hi-Z thermopile was delivered to JPL for testing and is shown in Figure 1. The crack visible in figure 1 makes that particular thermoelement loose without causing an open circuit during testing as described below. The individual thermoelectric elements and gold interconnects are clearly visible.

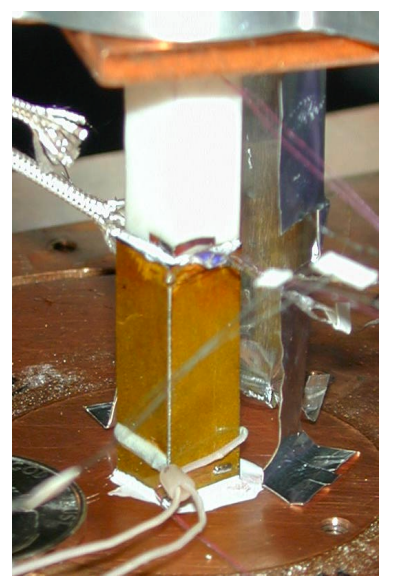

Figure 2. Thermoelectric Module Developed by Institute of Thermoelectricity in Chernivtsi, Ukraine. Figure also shows $0.3 \mathrm{~mm}$ thick heater/thermometer and TEC simulator above thermopile, and part of $\mathrm{Al}$ foil shielding.
Five thermopiles were purchased from the Institute of Thermoelectricity in Chernivtsi, Ukraine (designated Ukraine 1 to 5). These thermopiles are presumably fabricated in a very similar manner, but also contain a black substrate insulator on the hot and cold surfaces as well as a protective coating on the sides (Figure 2).

\section{MPS Container}

Several versions of the mechanical and thermal design of the MPS have been considered (Borshchevsky, 1997). The Hi$\mathrm{Z}$ design uses aluminized Kapton multi-foil insulation which can operate in vacuum if moisture is properly removed or with a xenon cover gas. The electrical output in vacuum is $40 \mathrm{~mW}$ while with Xenon it is less than half as much. Spring loaded titanium tie wires are used to hold RHU capsule holder firmly against the TEC both for good thermal contact and to help withstand high shock and vibration loads. A temperature difference of $225{ }^{\circ} \mathrm{C}$ was obtained with $1.1 \mathrm{~W}$ heat source resulting in $40 \mathrm{~mW}$ electrical output. The Hi-Z container has been impact tested to $1000 \mathrm{~g}$ 's (Allen, 2001).

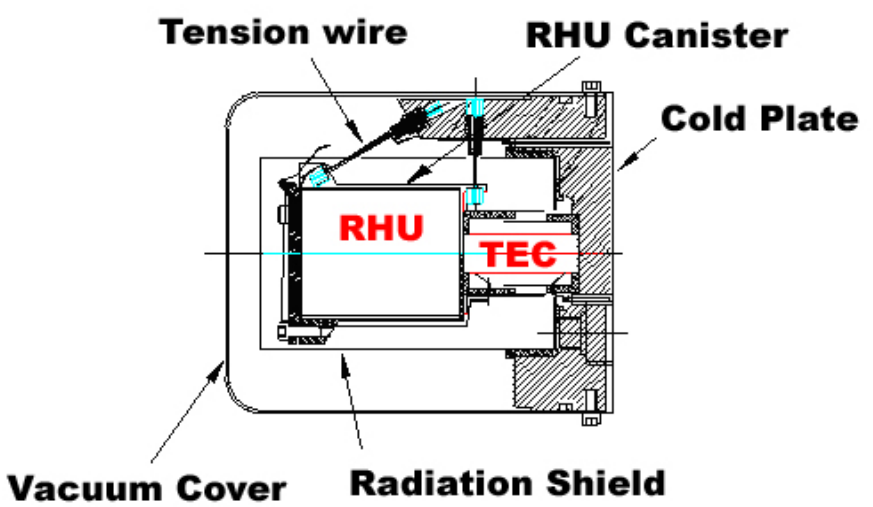

Figure 3. Diagram of MPS Container Designed and Built by Swales Aerospace.

The Swales Aerospace design is also a vacuum design but requires the RHU to be hermetically sealed, i.e. not to release He gas. The container shown in Figure 3 is $6.4 \mathrm{~cm}$ in diameter, $8.1 \mathrm{~cm}$ long weighing $300 \mathrm{~g}$. It is designed to direct $70 \%$ of the RHU heat to the TEC with a 150 to $170{ }^{\circ} \mathrm{C}$ temperature difference across the TEC. The RHU casing is held against the TEC with 6 wires providing 200 psi pressure at the TEC. A single layer of metallized kapton is used as the radiation shield. The Swales prototype had not yet been fitted with hermetic seals for testing in static vacuum. A very similar container has also been built and tested, with similar results (Pustovalov et al., 1999).

\section{Results}

The performance curves for various currents and temperatures were measured on the thermopiles using the measurement fixture pictured in Figure 2. A thin film heater and thermometer embedded in a $0.3 \mathrm{~mm}$ thick copper plate was attached to the hot side of the thermopile. On the other side of the copper plate was attached another thermopile for testing or a piece of glass ceramic with the same thermal conductance as a thermopile. This fixture was then sandwiched between two copper cold plates. Small 
thermocouples could also be attached to the outside surface of the thermopiles. Al foil was placed around the samples for radiation shielding. A current source was used as the load. The temperatures, voltages and currents were adjusted and monitored automatically by computer.

The thermopiles showed very linear I-V characteristics and therefore parabolic power curves as shown in Figure 4. Since the Peltier cooling depends on the current supplied by the thermopile, the hot side temperature will change if the heater power is kept constant; or the heater power must be changed to keep the hot side temperature constant (Figure 4). The constant heat measurement is more like the real application with an RHU, however the constant temperature measurement is probably more applicable for the evaluation of device performance and comparison with predicted results. This is due to heat losses which will depend on container or measurement fixture.
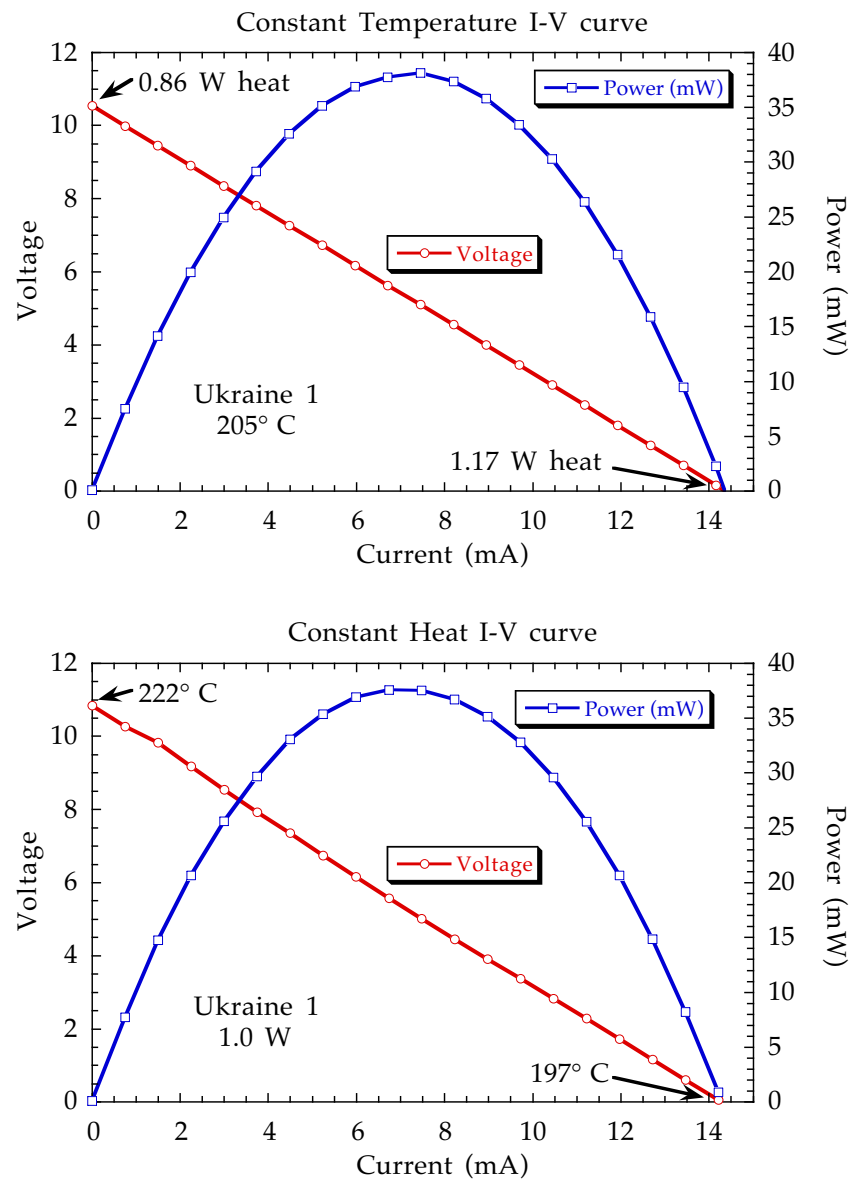

Figure 4. Examples of I-V Curves Measured on Thermopiles. Top: Measurement Using Constant Heater Temperature. Bottom: Measurement Using Constant Heater Power.

\section{Thermoelectric Converter Performance}

Such constant temperature I-V curves were measured for various hot side temperatures with all thermopiles. The hot side temperature is measured within the $0.3 \mathrm{~mm}$ thick heating plate. Thermocouples on the surface of the thermopiles were used to estimate the thermal contact resistances. For operation at $205^{\circ} \mathrm{C}$ heater temperature, the hot side of the thermopile elements was estimated to be $184^{\circ} \mathrm{C}$ and cold side of $31^{\circ} \mathrm{C}$. The Hi-Z thermopile has less thermal contact resistance, probably due to the lack of a substrate, providing a larger temperature difference: $190^{\circ} \mathrm{C}$ hot side and $28^{\circ} \mathrm{C}$ cold side.

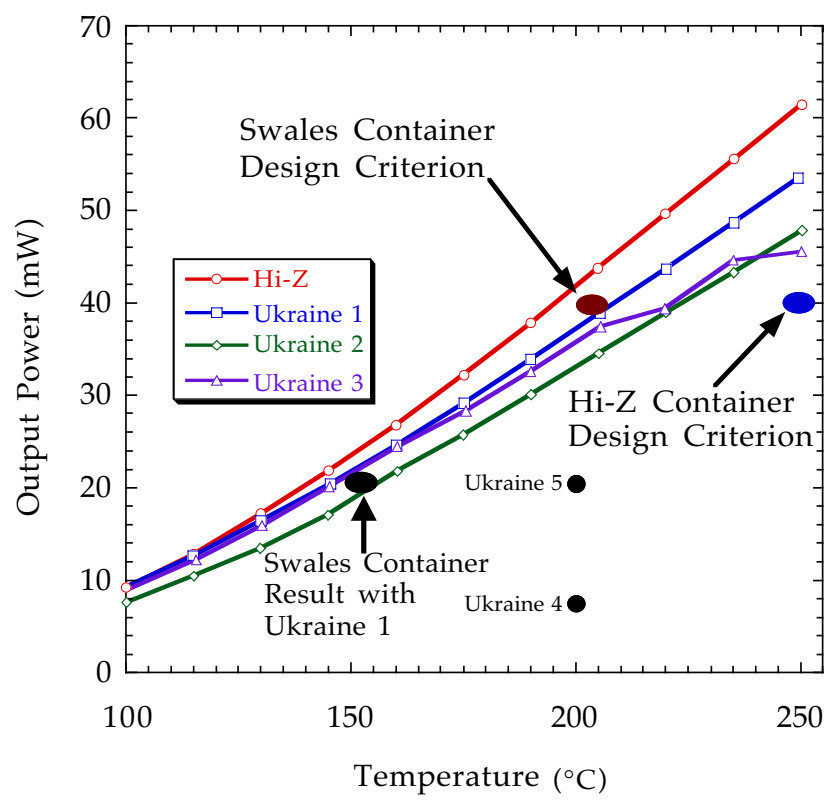

Figure 5. Maximum Power of Various Thermopiles as Heater Plate Temperature Varies.

As the heater temperature increases, the maximum output power increases as shown in Figure 5. These results can be directly used to estimate power output in a MPS with similar cold side temperature. The Swales $40 \mathrm{~mW}$ MPS container was designed to provide $150{ }^{\circ} \mathrm{C}$ to $170{ }^{\circ} \mathrm{C}$ temperature difference to the thermoelectric converter, which means about $200^{\circ} \mathrm{C}$ hot side. The best Ukraine thermopiles and $\mathrm{Hi}-\mathrm{Z}$ thermopiles meet this design criterion, providing about 40 $\mathrm{mW}$ power from a hot side temperature of about $200^{\circ} \mathrm{C}$. The $\mathrm{Hi}-\mathrm{Z}$ MPS container design is intended to provide a larger temperature difference, and hot side of nearly $250^{\circ} \mathrm{C}$, such that both the Ukraine and $\mathrm{Hi}-\mathrm{Z}$ thermopiles would easily exceed $40 \mathrm{~mW}$ at that temperature. Two of the Ukraine thermopiles, designated Ukraine 4 and 5, provided sporadic, low power with low voltage and less than half the internal resistance of the working thermopiles, indicative of electrical shorts that must have occurred during transport or test assembly. Thermopile Ukraine 3 shows some sporadic results in Figure 5 and critically failed (high internal resistance) after 4 days of operation.

\section{Life Testing}

Some thermopiles were then continuously tested, using a constant heater power (Figure 6). The Hi-Z thermopile performed well, showing no significant loss of power during 1 year of operation. The Ukraine 2 thermopile also showed no degradation after 3 months while Ukraine 3 failed after 4 days operation. 

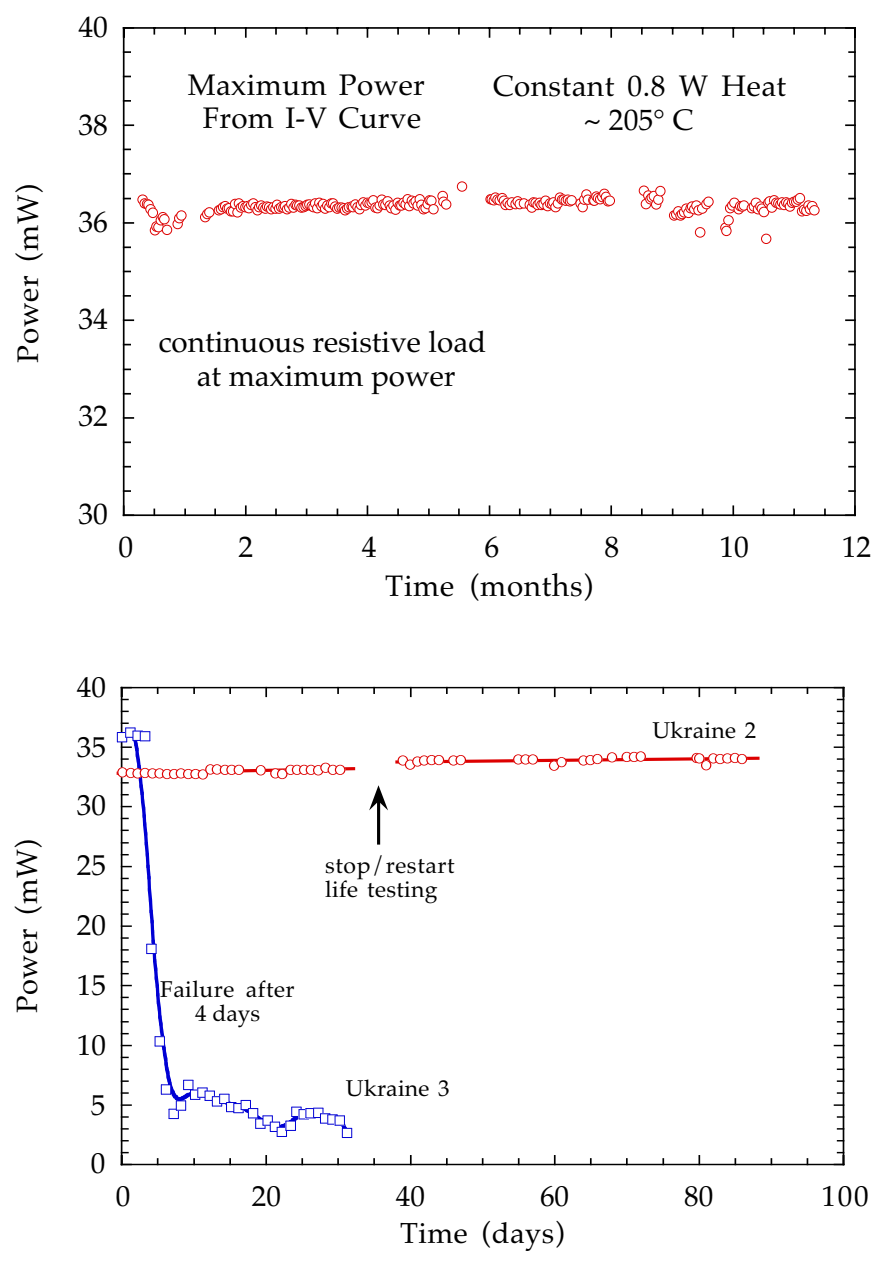

Figure 6. Long Term Testing of Thermopiles, With Constant Heat Input. Top: Hi-Z Thermopile Tested for Nearly 1 Year. Bottom: Ukraine Thermopiles.

\section{Swales MPS Container Performance}

Before delivery to JPL, the unit was tested at Swales: from $1.1 \mathrm{~W}$ heat input to a RHU simulator, the measured temperature difference was $138.6^{\circ} \mathrm{C}$ with a hot side of $163^{\circ} \mathrm{C}$. The container was found not to keep a vacuum and needed to be tested using a dynamic vacuum. Upon disassembly, significant outgassing of organics was noticed. This outgassing could have arisen from the epoxy used to fabricate a TEC simulator, the polyurethane resin intended fo use in the prototype only, kapton tape or even the metalized kapton shielding. Without a dynamic vacuum, the outgassing increases the heat conduction losses therefore decreasing the temperature difference across the TEC and reducing power output. These results were confirmed at JPL before installing the Ukraine 1 thermopile.

The Ukraine 1 thermopile was installed into the Swales container and the entire system tested in dynamic vacuum with $1.1 \mathrm{~W}$ heat input. Under open circuit conditions (no power drain) the hot side temperature reached $173^{\circ} \mathrm{C}$ with cold side of $33^{\circ} \mathrm{C}$, while under maximum power $(20.5 \mathrm{~mW})$ the hot side temperature stabilized at $161{ }^{\circ} \mathrm{C}$. These results are consistent with the previous results on the individual components: The TEC is performing within about $10 \%$ of that expected with the temperature difference provided but the Swales container is producing significantly less temperature drop than anticipated. Such a $20 \%$ decrease in temperature drop decreases not only the TEC efficiency but also the heat entering the TEC, giving a net $40 \%$ decreases in expected power output. The results reported here are in agreement with those on a similar design MPS (Pustovalov et al., 1999). Suggestions by Swales to improve the thermal performance include reduction of the titanium support wire diameter, elimination of thermal losses due to internal thermocouple and heater wires and improved insulation design.

\section{Conclusions}

Various components for a $40 \mathrm{~mW}$ Milliwatt Power Source powered by a single RHU simulator were tested. Thermoelectric converter thermopiles manufactured by Hi-Z Inc. in San Diego, California and the Institute of Thermoelectricity in the Ukraine performed as expected, producing $40 \mathrm{~mW}$ from a $140^{\circ} \mathrm{C}$ temperature difference. Some thermopiles were tested for up to 1 year with no observable degradation. The Milliwatt Power Source container designed and built by Swales aerospace provided less thermal insulation than anticipated, and was not yet able to hold a vacuum necessary for sealed operation. The combined container and thermopile unit was tested, producing $20 \mathrm{~mW}$ power.

\section{Acknowledgments}

The work described in this paper was carried out by the Jet Propulsion Laboratory, California Institute of Technology, under contract with the National Aeronautics and Space Administration.

\section{References}

Allen, Daniel T., and Murbach, Marcus S., "Milliwatt Radioisotope Power Supply for the PASCAL Mars Surface Stations," in proceedings of Space Technology and Applications International Forum (STAIF-2001), edited by M. El-Genk, AIP Conference Proceedings 552, New York, 2001, pp. 733.

Borshchevsky, Alexander; Chmielewski, Artur; Huang, Chen-Kuo; Bass, John; Bugby, David; Pustovalov, Alexey and Gusev, Vyacheslav, "Powerstick Development," IECEC-97, v. I, pp.465-468, 1997.

Chmielewski, Artur B., Ewell, Richard, "The Powerstick," AIAA-943816-CP (1994).

Elsner, N. B.; Bass, J. C.; Ghamaty, S.; Morris, C. C.; Baker, N. and Bass, J. A., "Fabrication of Milliwatt Modules" in proceedings of $18^{\text {th }}$ International Conference on Thermoelectrics, IEEE 99TH8407, p. 505 (1999).

Pustovalov, A., "Mini-RTGs on Plutonium-238: Development and Application" in proceedings of $18^{\text {th }}$ International Conference on Thermoelectrics, IEEE 99TH8407, p. 509 (1999).

Pustovalov, A.; Gusev, V; Borshchevsky, A and Chmielewski, Artur, "Experimental Confirmation of Milliwatt Power Source Concept" in proceedings of $18^{\text {th }}$ International Conference on Thermoelectrics, IEEE 99TH8407, p. 500 (1999).

Tate, R. E., "The Light Weight Radioisotope Heater Unit (LWRHU): A Technical Description of the Reference Design," Los Alamos Document No. LA-9078-MS (1982). 